PROBLEMS

OF EDUCATION

IN THE $21^{\text {st }}$ CENTURY

Vol. 78, No. 2, 2020

136

\title{
SCIENTIFIC ARTICLE PREPARATION: METHODOLOGY DESCRIPTION
}

\author{
Vincentas Lamanauskas \\ Šiauliai University, Lithuania \\ E-mail: vincentas.lamanauskas@su.It
}

\section{Introduction}

Scientific (academic) writing is continuous activity of every scientist (researcher), and therefore needs to be regularly advanced. Thus, it should be wrong to assume that writing proficiency is achieved once and for all. The skills of academic writing are essential for the independent acquisition of scientific knowledge and for disseminating the acquired information, i.e. sharing knowledge with others. On these grounds, it is worth remembering that a fully completed research paper, the clear results of the conducted research and specific and valid conclusions act as prerequisites for writing a good scientific article etc. Another trivial but important point is that writing an article (or other research paper) is barely a study itself, but only the presentation, dissemination and publicity of the findings. Consequently, even properly carried out research (exploration, examination etc.) and the obtained significant results may fail to be appropriately presented, and the importance of the produced results may simply 'disappear' in a poor description.

Scientific writing and critical/analytical reading are distinguished as the two basic elements of scientific literacy. Each of these elements possesses individual principles and characteristics. What is more, these two are closely linked. In practical terms, scientific writing is the one used by scientists to introduce the scientific community, which is due to writing specificity. There is no doubt that scientific literacy is the completeness of different abilities. The previous editorials attempted to address the aspects of article titles, abstracts, keyword (Lamanauskas, 2019a) and introduction writing (Lamanauskas, 2019b). This time we intend to briefly discuss the most important issues of describing research methodology, which is a critical part of the scientific article. Hence, a crucial point is that this examination applies mainly to the field of social sciences, i.e. to the scientific articles of education. Natural and social sciences are clearly distinguished considering the studied object of these sciences and the main methodological differences in their research (Maslauskaite, 2008).

Research methodology differs depending on the type of research and other features. As more or less general part of research methodology is examined further, it is useful to mention that the concept of research methodology is quite different because of varying approaches. For example, according to the recommendations provided by the APA (editions 6 and 7), the section of research methodology is called 'method', which is not entirely reasonable. A method is generally accepted as a set of certain rules, means and techniques of cognition and operation, i.e. a set of appropriate rules, measures requirements, etc. performing a specified research task to achieve a particular result. Meanwhile, the methodology covers the entire organization of research activity. Any research must be methodologically substantiated, i.e. the problem must be properly identified and named (formulating a topic is a verbalized problem) thus discussing the research concept, hypothesis, methods, design, etc., which, according to Kardelis (2007), is treated as research methodology that must be described in a clear and orderly manner. Kallet (2004) puts emphasis on the importance of avoiding confusion and ambiguity. 


\section{Describing Methodology}

The description of research methodology typically distinguishes certain parts (subsections of the text), including general research characteristics (frequently presented as research design), research sample (or simply research participants), research instrument and procedures and data analysis (including statistical analysis). The number and structure of such subsections may vary. Scientific text is usually constructed from individual elements each of which is independent in its own way, while on the other hand, it is uniquely related to the other elements of the text. A separate section or subsection is most frequently focused to the development of the specified main argument. Nevertheless, there are some common features important for describing research methodology. Hence, the next step involves examining each of them.

\section{General Characteristics of Research}

The general characteristic of research is a crucial element of research methodology, which involves the basis (foundation) of the whole research. In other words, it is like an introduction to the methodology of a particular study as a complete product, including the design of the conducted research and the interpretation of the most important arguments. Describing (presenting) research design, defining research paradigm and briefly discussing researcher's 'journey' prior to investigation and a possible impact of researcher's experience are relevant tasks. Subjectivity usually manifesting itself in the qualitative study is useful to reveal. This section discusses the applied research methods as techniques for gaining certain cognitive and practical information. The application of a separate research method must be validated thus clarifying this is the exact method applied for obtaining the required information. After all, the properly chosen method, along with researcher aptitude, helps to reveal the essence of phenomena (Gintalas, 2011). On the other hand, the research method may affect the final results. The most important (basic) research methods are indicated first and then followed by other techniques, which provides greater clarity so that each reader should easily understand and, if necessary, continue or repeat the study in the future. Practice shows that researchers quite often misinterpret such terms as 'research type', 'research level', 'research method/technique', 'research performance', 'research design', 'research instrument', etc. Thus, such confusion must be avoided. Table 1 provides some examples of inappropriate descriptions. 
PROBLEMS

OF EDUCATION

IN THE $21^{\text {st }}$ CENTURY

Vol. 78, No. 2, 2020

138

Table 1

Description examples of the general characteristics of research

\begin{tabular}{|c|c|}
\hline Example & Comment \\
\hline $\begin{array}{l}\text { General Background of Research } \\
\text { This study employed mixed method design in which quantitative } \\
\text { and qualitative approaches were used in collecting data. It is } \\
\text { stated that the main core of mixed method design is the use of } \\
\text { multiple methods that belong to both quantitative and qualitative } \\
\text { paradigms. }\end{array}$ & $\begin{array}{l}\text { The description is superficial and vague. One } \\
\text { refers to 'mixed method design', whereas the other } \\
\text { sentence introduces 'multiple methods'. The same } \\
\text { situation is noticed discussing terms 'approaches' } \\
\text { and 'paradigms'. }\end{array}$ \\
\hline
\end{tabular}

General Background of Research

In order to examine university students' anxiety about mathematics through different variables, a mixed method research design, one of the descriptive research methods, was employed in this study. This research includes an integrated approach of both qualitative and quantitative models, which involves the collection, analysis and combination of qualitative and quantitative data.

\section{General Backgound}

This quantitative experimental research was carried out with a sample of ${ }^{* * * * *}$ students from a high school about their experience with $\mathrm{Pl}$. An instrument comprising 25 items from trigonometry unit was developed to gather data, which were collected at the end of the autumn semester of 2018-2019 academic year.
Total confusion between the terms 'research design' and 'research method'. Models are described later. Still, it remains unclear how this relates to mixed method research design.

The general characteristics of research are not clearly specified. The description contains the 'elements' of the sample and design, but research as a whole is unclear.

\section{Reseach Methods}

In order to solve the tasks, the complex of theoretical (analysis and synthesis of pedagogical, psychological, scientific and methodical literature for comparison, comparison of different views on the investigated problem) and empirical methods of research, qualitative and quantitative analysis of the results were carried out with the use of mathematical statistics methods.
A complete 'mix'. An attempt has been made to describe the entire research methodology in one short paragraph.

Note: The language used in the examples provided is not corrected.

Researchers frequently forget to indicate the type, level and scope of the research conducted. Therefore, quite a few articles fail to report the general characteristics of research, and the section introducing methodology begins by presenting information about research participants. Research time, including the circumstances the study was carried out, is another highly important aspect. This is very essential for interpreting the obtained results, analysing findings, etc. Similarly to the other cases, a universal methodological rule states that other researchers should manage to repeat particular research (for example, an experiment etc.) and evaluate whether the results are reproducible. For example, research may involve a meaningful topic in a particular area of science, but very limited in its scope (for example, related to only one university, secondary school, small organization, department, group of people ,etc.). In this case, the findings may not be applied to a wider audience. 
The description of the research sample (research participants) is a crucial element. The reader must clearly understand the reasons for how and why research participants are selected for a particular study. However, significant differences in sampling for qualitative and quantitative research are available. In the case of empirical-quantitative research, requirements for the research sample (if applicable) are extremely stringent. In contrast, similar requirements for empirical-qualitative research are more flexible. Qualitative research finds important the cases providing information in terms of the research problem (question). In most cases, three main options are possible (Rupsiene, 2007): a) sample size of the conducted research is predicted in advance; b) research sample is not planned in advance but data are collected until repetition and decreased informativeness are observed; c) preliminary sample size is estimated, but the sample is expanded in the data collection process. A relatively small number of research participants is selected for qualitative research in order to analyse each case in as much detail as possible. Context also plays a significant role in such analysis (Hammersley, 2013). Table 2 provides some examples of the incorrect descriptions of samples.

However, in this case, a certain stereotypical view of researchers is observed, which shows that the research sample, in view of qualitative research, it is not necessary to validate. For example, the arguments such as 'a large sample of research participants is not required', 'this is phenomenological research, and therefore a small sample is validated', etc. are put forward, which is a wrong position. Another common misconception is the research sample described together with research design. Such options should be avoided. A detailed description (characteristics) of research participants (research sample, group, participants) shows the representativeness of the carried out research.

\section{Table 2}

\section{Description examples of the research sample (participants)}

\begin{tabular}{|c|c|}
\hline Example & Comment \\
\hline $\begin{array}{l}\text { Sample } \\
\text { The questionnaires were distributed online to the senior faculty } \\
\text { members of }{ }^{* * * *} \text { university on Google Docs. } 112 \text { completed } \\
\text { questionnaires were returned to the researchers }(47.2 \% \text { female). } \\
\text { Respondents ages were } 33-39(6.4 \%), 40-49(46.8 \%) \text {, and } 50+ \\
(46.8 \%) \text {. }\end{array}$ & $\begin{array}{l}\text { Inappropriate description. The sample volume } \\
\text { and sampling method are not specified. Lack of } \\
\text { information on the reliability and representativeness } \\
\text { of the sample. Data on research population is } \\
\text { completely missing. }\end{array}$ \\
\hline
\end{tabular}

Sample of Research

Purposive sampling was used and a selected well-resourced high school in a province in ${ }^{* * * * * *}$ was used due to non-hindrance of classroom access to the three junior Natural Science teachers who were using ICTs in their subject teaching. Purposive sampling also afforded deep insights of the teachers and in particular their school contexts use of ICT.

\section{Sample}

The sample for this study was 92 high school teachers of English in Pidie Regency. They were asked to fill in a questionnaire that inquired about their professional development programs and effects undertaken for their professional development.

\section{Sample}

The subject of the research was the students of IV grade and the teachers in SD IT Umar Bin Khattab Kudus. The sample consists of 15 students and 5 teachers. Samples were taken using cluster random sampling technique.
Inappropriate description. The sample, characteristics of the respondents, etc. are not validated.

Inappropriate description. The sample volume is not validated (why 92?). A single sentence describes the sample. Demographic information about research participants is not provided.

Inappropriate description. The sample is not validated. Demographic information about research participants is not provided. The sampling procedure is not clarified.

Note: The language used in the examples provided is not corrected. 
PROBLEMS

OF EDUCATION

IN THE $21^{\text {st }}$ CENTURY

Vol. 78, No. 2,2020

140

For describing the research sample, providing as detailed demographic information as possible about participants is necessary. A breakdown of participants according to the gender is frequently missed, even though the volume of the sample (or samples) is large enough. The sample volume is mentioned, which is a very important point. An appropriate sample volume can be considered as a reliable instrument for arriving at valid and comprehensive conclusions. The volume of the sample is determined by the purpose of research, the nature of research questions, available material resources and time expenditure. It is equally important to specify selection criteria for research participants (e.g. a researcher is interested in gifted children, learners with special needs, etc.). In other words, we need to be sure that research participants are selected with reference to the essential characteristics the researcher is focused on. Also, mentioning the sampling method, i.e. probabilistic, non-probabilistic, etc. is of utmost importance.

Next, the research population should be considered. Again, it is common for scientists to describe the research sample, but still it remains unclear what population is represented by the sample obtained. Certainly, in some cases, a detailed description of the population is not required, for example, when a specific group of people is researched, and the findings are not generalized. Thus, the aim of the conducted research is not to generalize the research findings of the entire group of people (target population). In this case, it is not necessary to define population, as instead of the term 'sample', another term 'research / study group' is used. It should be a mistake to assume that only people are involved in research. The sample may consist of different objects such as the sources of scientific information (books, articles, other papers, etc.). For example, the carried out analysis of research results (meta-analysis) combines and statistically analyses the results of many researches thus resulting in the so-called integrated result. Research paper selection and inclusion in the performed analysis are relevant features. In general, the selection of the sample should not be vague, it must be clear in how and why. The research sample (participants) are usually described before research instrument and/or procedures.

Research ethics is an important aspect. As for quantitative research, information on the issues of research ethics is often provided in the same subsection together with the sample (participants). In the case of qualitative research, the separate section of 'research ethics' is created more frequently (for example, What ethical procedures were followed? How was ethics/ ethical aspects ensured/catered for? How was permission obtained to conduct the research?). Practice shows that quite often research ethics is simply forgotten or not given attention it deserves.

\section{Research Instrument and Procedures}

Any research is impossible without proper tools/instruments. There are quite a variety of instruments used in social research practice. Certainly, instruments may vary depending on the field (or direction) of science. For example, sociologists are more likely to use instruments suitable in survey design, while psychological research is more specific to testing and appropriate forms of instruments like tests, which is due to science itself, i.e. the logic of cognitive domain. Sociologists are more concerned with the amount of people involved, whereas psychologists concentrate on individual qualities.

No matter what research instrument is used, it must be valid and reliable. Thus, two options are available. The first looks at the researcher him/herself creating the required research instruments like a test, a questionnaire, etc. Therefore, it is necessary to determine the validity and reliability of a certain type of instrument and to specify other psychometrical properties. Besides, it is also useful to briefly describe whether the developed instrument has been piloted. The second option considers the developed and put into practice instrument applied for research purposes. In most cases, such types of research instruments are standardized and suitable for 
collecting information. Hence, it is worth keeping in mind the procedures for the transcultural adaptation of the already developed research instruments. Table 3 provides some examples describing research instruments and procedures.

Qualitative research demonstrates that the types of the main research instruments/methods for data collection include interviews, observation and document analysis. The introduced techniques are not going to be discussed in detail, because focus is shifted on the description process. A research article frequently indicates that an interview has been applied, which shows that interviews may vary, i.e. an interview is a survey (one of the types of survey strategy). The description needs to be 'reduced' to the specified research method such as a semi-structured individual interview, a semi-structured group interview, face-to-face interviews, etc. Interview instrument such as an interview sheet, an interview protocol, etc. is also must be considered. As a rule, such an instrument as well as observation may be set out in the appendixes to the article. According to Creswell (2009), observation is a data collection method that helps the researcher to get data on individual behaviour and activities in the research field. Still, observation can be structured, unstructured, participant (participatory)/non-participant (non-participatory), overt (disclosed)/covert (undisclosed) etc. Along with observation as a data collection method, observation techniques (e.g. observation cards, sheets, protocol, etc.), course, conditions and circumstances are described. Hence, according to Ciesielska et al. (2018), an observation is one of the most diverse research methods in social sciences. 
PROBLEMS

OF EDUCATION

IN THE $21^{\text {st }}$ CENTURY

Vol. 78, No. 2, 2020

142

Table 3

Description examples of research design and procedures

Example
Data Collection and Analysis
In data collecton, researchers were included in the scope of research and
nonstructured interview form including open ended questions was carried
out. To this aim, participants were given A4 blank papers and asked to write
down the problems they have experienced in classroom management with
their probable reasons. Data colleted were analyzed using content analysis
and categerized. Then the frequency values of the data were determined and
interpreted.
interpreted.

Instrument and Procedures

To achieve the assigned tasks the following research methods were used: general scientific methods of theoretical level: analysis and synthesis, systematization and generalization of research results in the ascertaining and the formatine stages of experiment, theoretical modeline (Bogdan \& Biklen, 1982; Cohen, Manion \& Morrison, 2007; Zatsiorsky, 2006).

\section{Methods and Instruments}

The methods used in the research are the method of theoretical analysis and the descriptive method. As a research technique we used scaling conducted by using the instrument named RPCFTQ (The reflective practice as a changing factor of teaching quaity) especially designed for the needs of the research and based on the characteristics of the basic teaching skills given by Kyriacou (2001) which we have linked to the elements of the reflective practice from the theoretical part of the paper. The research sample consists of 202 participants.

\section{Instrument and Procedures}

The survey was conducted using a targeted questionnaire containing 25 variables, that included questions on demographics/family situaton; employment; economic issues; barriers to education; attitudes towards education; and general issues of optimism, self-esteem and happiness.

The guidebook used in the focus groups included 10 questions concerning the termination of learning, evaluation of their decision, their attitudes towards the importance of education and their future plans.

Note: The language used in the examples provided is not corrected.

Questionnaires and tests are probably the most common types of instruments used in quantitative research. The same applies to methodological rules. It is worth mentioning certain methodological 'chaos' due to the lacking common approach to tests and/or questionnaires. For example, according to Cohen and Swerdlik (2018, p. 7), 'a test may be defined simply as a measuring device or procedure'. Meanwhile, Mertler $(2003$, p. 6) found a test as 'a formal set of questions or tasks often administered to a group of students that address particular cognitive capabilities learned in a specific course or subject area.' The applied concept 'questions' is barely characteristic of tests. The questions/tasks from a test are very often (in published literature) called 'test items' that are the smallest units constituting the test. Researchers should avoid confusion and, whenever possible, reference to test tasks as to questions, which is often observed in the process of reading research articles. Linguistic peculiarities should also be considered. The types of instruments mentioned in other languages are very clearly specified, e.g. questionnaire (rus. Анкета, lith. anketa), high-volume questionnaire (rus. Опросник, lith. klausimynas). is important:

For describing the above introduce types of instrument, answering a few key questions 
- What are the psychometric properties of particular instrument?

- How validation procedures were proceeded by researchers?

- What is the reliability of particular instrument?

Researchers frequently mention that the questionnaire has been applied in the conducted research; however, they basically provide no information on the content of such type of instrument, i.e. there is little indication of the content of the questionnaire that forms the basis for data collection. Thus, whenever possible, research instrument is presented as an appendix of the article. Otherwise (e.g. due to an excessive volume of the article), researchers should give some example questions in the appendix. Another option is providing a link to a source of information or a repository. Overall, this is not enough to make sure that the test and/or questionnaire is standard and valid without other procedures.

Research procedures cover research performance and stages. Test procedures should be described in a concise and maximally clear manner. For example, the statement 'an interview took place in very different settings' is correct but unspecified. Information on the mentioned different environments is not provided. A researcher writes in a similar example that 'data have been recorded and then encrypted'. No additional information is provided

\section{Data Analysis}

Either quantitative or qualitative data analysis is performed in each research. Both procedures are common to research practice thus not limiting to quantitative data analysis only. The situation depends on various factors, but analysis must allow achieving a high level of interpreting the obtained data.

Quantitative analysis methods are based on the use of applied statistical software packages to process the collected data (e.g. SPSS, Statistica, etc.). The authors often prefer describing a statistical program that should not be accepted a priority, i.e. it is irrelevant what program has been employed for data analysis. The type of analysis and author's substantiation are more important. Hence, it is appropriate to indicate the employed statistical programs (e.g. SPSS, QDA Miner Lite, Transana, MAXQDA, etc.) at the end of this section. Table 4 provides some examples of inappropriate descriptions of data analysis. 
PROBLEMS

OF EDUCATION

IN THE $21^{\text {st }}$ CENTURY

Vol. 78, No. 2, 2020

144 Table 4

Description examples of data analysis

\begin{tabular}{l} 
Example \\
\hline Data Analysis \\
Data gathered were tabulated using simple percentages and were statistically \\
analysed using IBM SPSS Statistics 23 software and Chi square test was \\
used as a quantitative measure to determine whether a relationship exists \\
within the given set of categorical variables.
\end{tabular}

Data analysis

Data analysis have three objectives; getting a feel for the data, testing the goodness of data and testing the hypotheses developed for the research (Sekaran \& Bougie, 2010). The data analyses methods used were Descriptive Statistics and Pearson Correlation.

\section{Data Analysis}

Overall, there were seven items in the questionnaire that inquired about the professional development of these teachers. The choices prepared for the items were "Yes", „No", and „No answer". The frequency of occurrence of answers to the items was then converted into percentages for the reporting of the results.

\section{Data Analysis}

The respodents' answers to the selected questions were analysed. For a statistical verification of the aim of the research, t-test, Pearson's chi-squared test and Multiple linear regression were used.

Data Analysis

Data obtained through the survey was analysed by SPSS23. Qualitative data was analysed by content analysis.

\section{Comment}

The description is extremely weak and unclear. The reference to the statistical program provides no information about the analysis itself. The term 'relationship' should not be used in this case.

Inappropriate description. The information source of the objectives of data analysis is reinterpreted, but the analysis itself is not explained. Descriptive statistics is not a method of analysis due to a variety of the measures of descriptive statistics. After all, descriptive statistics is a set of methods for data systematization and graphical representation.

Data analysis procedures are confused with the description of the instrument. The text is linguistically incorrect. Insufficient data analysis.

The description is extremely 'poor' and incorrect. The first sentence is uninformative. It is not clear how to statistically verify research purpose.

A typical example of an incorrect description. The statistical program is mentioned. The applied type of content analysis is not specified and validated.

Note: The language used in the examples provided is not corrected.

Statistical analysis should not involve an extensive description of the basic statistical procedures. This is generally well-known among academic community and therefore unnecessary. It is common for articles to describe statistical analysis in great detail, which is usually only statistical jargon. Similar articles most frequently make a little attempt to solidly ground the research done in a theoretical framework. Another observation is related to the description itself, for example, paragraphs are excessively long, and therefore the reader is lost. On the contrary, a paragraph often consists of a single sentence, which is also wrong.

Qualitative data analysis is more diverse. According to Luobikiene (2008), in this case, no single methodological structure is observed. A variety of qualitative research determines the diversity of qualitative data analysis, including various approaches, methodological positions of researchers, etc. This is both a data processing (Creswell, 2009) and a creative process. As a rule, it occurs during and after data collection (Patton, 2002). An exceptional and specific part of qualitative research data analysis is the researcher's reflection in terms of the research process, findings and insights. There are cases when the researcher seeks to summarize the obtained data. Hence, it is important to keep in mind that qualitative research does not generalize data, i.e. it is barely treated that the revealed aspects are specific to the entire population. 


\section{Summing-up}

In conclusion, the description of research methodology must be transparent, informative and provide the reader with a clear picture of the analytical procedures used (including statistical). In other words, every researcher must be very specific in order that the one who wants to replicate research knows exactly what has happened and how it has been done. There must be no uncertainty.

It is worth noting the general use of the language for the purpose of describing research methodology. The past tense is usually used for describing what was done. It may be in the active or passive voice. The present tense is applied for presenting diagrams and figures. Methodologically incorrect and emotional statements are hardly tolerated in the text. Here are some examples of such statements from research articles:

'I have never liked quantitative research, because it claims to be actual knowledge; however, basically it only 'pretends' to be objective ...

'My personal sensitivity can be felt in the research ...'

'This research should be hardly accepted as a textbook of advice ...'

'The research is quite extensive because it has been difficult to narrow the field ....'

'The research topic itself basically dictated the research method ....'

'The research should be structured with reference to the investigated data ...'

Research methodology is known to differ subject to the type and objectives of the carried out research. However, research methodology must explain the general scientific approach employed by the researcher in a certain study. In other words, the researcher him/herself seems to answer the question whether his/her study (analysis) is really based on arguments or empirical evidence. For example, research/analysis can be entirely literature-based. In this case, the methodology of theoretical analysis is described (e.g. methods for collecting the theoretical-descriptive material, the theories validating analysis, etc.). There are those who trust that such analysis is much simpler and easier than empirical research. On the contrary, in many cases, such analysis is much more integrated and complex. Unlike empirical research, design in theoretical papers must be explained from the very beginning. In any case, it is important to understand that the section of research methodology needs to be described in detail. According to researchers, such technique allows the reader to assess the validity of the presented research findings and conclusions (Müller-Staub, 2012).

\section{Note}

Some examples have been taken from the manuscripts submitted for journals Journal of Baltic Science Education and Problems of Education in the $21^{\text {st }}$ Century.

\section{References}

Ciesielska, M., Boström, K. W., \& Öhlander, M. (2018). Observation methods. In M. Ciesielska, \& D. Jemielniak (Eds.), Qualitative methodologies in organization studies (pp. 33-52). Palgrave Macmillan, Cham. https://doi.org/10.1007/978-3-319-65442-3_2

Cohen, R. J., \& Swerdlik, M. E. (2018). Psychological testing and assessment: An introduction to tests and measurement. McGraw-Hill Education. 
Vincentas LAMANAUSKAS. Scientific article preparation: Methodology description

PROBLEMS

OF EDUCATION

IN THE $21^{\text {st }}$ CENTURY

Vol. 78 , No. 2, 2020

146

Creswell, J. (2009). Research design: Qualitative, quantitative, and mixed methods approaches. SAGE.

Gintalas, A. (2011). Metodologijos ir metodo samprata [The concept of methodology and method]. Socialiniu mokslu studijos / Societal Studies, 3(3), 983-996.

Hammersley, M. (2013). What is qualitative research? Bloomsbury Academic.

Kallet, R. (2004). How to write the methods section of a research paper. Respiratory Care, 49(10), 12291232.

Kardelis, K. (2007). Moksliniu tyrimu metodologija ir metodai: edukologija ir kiti socialiniai mokslai: vadovèlis. 4-asis leidimas [Research methodology and methods: Education and other social sciences): Textbook. 4th ed.] (p. 88). Lucilijus.

Lamanauskas, V. (2019a). Scientific article preparation: Title, abstract and keywords. Problems of Education in the 21st Century, 77(4), 456-462. https://doi.org/10.33225/pec/19.77.456

Lamanauskas, V. (2019b). Scientific article preparation: A comprehensive introduction. Problems of Education in the 21st Century, 77(6), 688-694. https://doi.org/10.33225/pec/19.77.688

Luobikienè, I. (2008). Socialiniu tyrimu metodika [Methodology of social research] (6th ed). Technologija.

Maslauskaitè, A. (2008). Mokslo tiriamojo darbo metodologiniai pagrindai [Methodological basis of research work]. Generolo Jono Žemaičio Lietuvos karo akademija.

Mertler, C. A. (2003). Classroom assessment: A practical guide for educators. Routledge.

Müller-Staub, M. (2012). The importance of clear methods descriptions in research papers. Acta Paulista de Enfermagem, 25(spe2), iii-iv. https://doi.org/10.1590/S0103-21002012000900001

Patton, M. Q. (2002). Qualitative research and evaluation methods (3rd edition). Thousand Oaks.

Rupšiene, L. (2007). Kokybinio tyrimo duomenu rinkimo metodologija [Qualitative research data collection methodology]. Klaipėdos universiteto leidykla.

Received: February 08, 2020

Accepted: April 02, 2020

Cite as: Lamanauskas, V. (2020). Scientific article preparation: Methodology description. Problems of Education in the $2{ }^{\text {st }}$ Century, $78(2), 136-146$. https://doi.org/10.33225/pec/20.78.136

Vincentas Lamanauskas
PhD, Professor, Senior Researcher, University of Šiauliai, Institute of Education, P. Visinskio Street 25-119, LT-76351 Siauliai, Lithuania.

E-mail: vincentas.lamanauskas@su.lt

Website: http://www.lamanauskas.puslapiai.It/;

https://www.researchgate.net/profile/Vincentas_Lamanauskas

ORCID ID: http://orcid.org/0000-0002-4130-7899 